\title{
Screening of an ethnomedicinal plant Erythrina indica Lam. for their antimicrobial, antioxidant and phytochemical properties against ear pathogens
}

\author{
Kaushal Aparna禺, Navneet and Kumar Sanjay
}

Received: 23.05.2018

Revised: 20.08.2018

Accepted: 14.11.2018

\begin{abstract}
A significant use of plants and their products as herbal medicine is the traditionally important mode of treatment all over the world. The present work is aimed to evaluate the therapeutic potential of Erythrina indica leaves extracts. The crude extract of Erythrina indica leaves was evaluated for antimicrobial, antioxidant and phytochemical analysis against ear pathogens. $E$. indica crude extracts showed moderate antimicrobial activities. The Minimum inhibitory concentration $3.12 \mathrm{mg} / \mathrm{ml}$ of methanol extract was found effective against $S$. epidermidis and $\boldsymbol{H}$. influenzae. The fungitoxic effects of the methanol extract on the mycelial growth of test fungi was determined which is found above $600 \mu \mathrm{g} / \mathrm{ml}$. Antioxidant activity of methanol extract of Erythrina indica leaves was found lower than ascorbic acid by DPPH free radical scavenging activity. The phytochemical screening for $\mathrm{MeOH}$ extract of $E$. indica revealed the presence of phenols, flavonoids, glycosides, alkaloids, steroids and tannins. This study supports the use of Erythrina indica in herbal medicine and as a base for the development of new drugs and phytomedicine in rationale for its use in treatment of ear diseases.
\end{abstract}

Key words: Antimicrobial activity, antioxidant activity, agar well diffusion method, poisoned food technique, phytochemical screening, Minimum inhibitory concentration, 2,2-diphenyl-1-picrylhydrazyl assay.

\section{Introduction}

Ear infections usually occur in external auditory canal and small space behind the eardrum i.e. the middle ear. These are most ordinary ailments nowadays experienced in medical practices and common problem diagnosed in infants, children and adults as ear is one of the most delicate sense organ. Lack of proper care may lead to ear infections. The major causative agents responsible for ear infections are bacteria (Pseudomonas aeruginosa, Staphylococcus aureus, S. epidermidis, Streptococcus pneumoniae, Escherichia coli, Proteus mirabilis, Haemophilus influenzae) and fungi (Aspergillus niger, A. fumigatus, A. flavus, Candida albicans) (Roland and Stroman 2002; Rosenfeld, et al., 2006; Dhingra, 2007; Aneja, et al., 2010). Compounds which show either inhibition or cidal activity against microbes is believed to have antimicrobial activity. A wide range systemic screening and evaluation of plant extracts from various parts of plants i.e. root, bark, Author's Address

Department of Botany and Microbiology, Gurukul Kangri University, Haridwar-249404, Uttarakhand, India. E-mail.: akaushal53@gmail.com flowers, leaves and seeds are being used for medicinal purposes and represent a continuous effort to obtain new compounds with potential antimicrobial properties (Shariff, et al., 2006; Maobe, et al., 2013). From ancient time, herbal medicine was practiced for the treatment of various diseases by traditional practitioners. They have learned plants use by trial and error method to differentiate plants with beneficial effects from those which could be lethal (Jagessar, et al., 2008). Presently, a lot of attention is being paid towards the significant use of antioxidants from natural resources i.e, common and aromatic, therapeutic plants and spices etc are essential supply of natural antioxidants. Either synthetic or natural, both types of antioxidants help to prevent effect of free radicals which are unstable and can damage adjacent molecules like proteins, carbohydrates or lipids etc, cause oxidative stress and induce cellular damage resulting in several chronic and degenerative disorders i.e., ageing, cancer, cardiovascular disease, immune-suppression, etc (Young and Woodside 2001; Barber 
and Harris 1994). A lot of studies are being focused on antioxidants from natural resources. Many in vitro studies fully supported that natural antioxidants procured from therapeutic plants are providing protection against oxidative degradation by free radicals in biological system (Cao, et al., 1996). Erythrina indica Lam. also known as Paribhadra (Sanskrit) and Coral tree (English) belongs to the family "Papilionaceae". It is a fast growing tree up to 18 meters in height, the leaves are trifoliolate and flowers are borne in dense racemes, coral red with small conical dark coloured prickles, commonly found in the wild tropics and deciduous forests of India. E. indica bark is traditionally used as febrifuge, anti-bilious, antidiarrhoeal and antirheumatic, also used for treatment of liver trouble, asthma, dysentry, joint pain, fever and leprosy and known to have analgesic, anthelmintic, antiulcer, antioxidant and sedative properties (Jesupillai, et al., 2008; Sakat and Juvekar 2010 Amir, et al., 2011). Therefore, this study was conducted to evaluate antimicrobial and antioxidant activities of $E$. indica in different extracts. Screening for phytochemical constituents provide more widespread knowledge on the antimicrobial and antioxidant properties of plant extracts and their effects on ear pathogens causing ear infection.

\section{Material and Methods}

Preparation of Extract: Erythrina indica leaves were collected, cleaned, shade dried and then grinded in powdered form with electric grinder. Plant extracts were prepared by soaking $200 \mathrm{~g}$ of powdered leaves material in $600 \mathrm{ml}$ of four different solvents i.e. petroleum ether (PET), acetone (ACE), methanol $(\mathrm{MeOH})$ and water $\left(\mathrm{H}_{2} \mathrm{O}\right)$, successively extracted for $72 \mathrm{~h}$ in the soxhlet extractor (Kumar, et al., 2014). The crude extract obtained was filtered through a sterilized Whatman No. 1 filter paper and evaporated in vacuum evaporator. Extracts were stored at $4{ }^{\circ} \mathrm{C}$ until further use.

Test Microorganisms: The bacterial and four fungal strains causing ear infections used in this study were Streptococcus pneumoniae (MTCC 655), Staphylococcus epidermidis (MTCC 435), Haemophilus influenzae (MTCC 3826), Aspergillus niger (MTCC 921), A. fumigatus (MTCC 870) and A. flavus (MTCC 277).

Preparation of Inoculums: Stock cultures were maintained at $4{ }^{\circ} \mathrm{C}$ on slants of nutrient agar. Active cultures for experiments were prepared by transferring a loopful of cells from stock cultures to test tubes of Mueller-Hinton broth (MHB) for bacteria and Sabouraud Dextrose Broth (SDB) for fungi. These were incubated without agitation for $24 \mathrm{~h}$ at $37^{\circ} \mathrm{C}$ and $25^{\circ} \mathrm{C}$ respectively.

Antibacterial testing: The plant extracts were screened for antibacterial activity by agar welldiffusion method (Ahmed, et al., 1998). Bacterial suspensions were prepared in nutrient broth and incubated at $37^{\circ} \mathrm{C}$ for $12-16 \mathrm{~h}$ for making a turbid suspension equivalent to McFarland turbidity standard $0.5 .0 .1 \mathrm{ml}$ of incubated culture was added to sterile Mueller Hinton Agar aseptically in petri plate. A $6 \mathrm{~mm}$ diameter agar wells was made aseptically in solidified agar medium with sterile cork borer and $45 \mu \mathrm{l}$ of the extracts of $200 \mathrm{mg} / \mathrm{ml}$ final concentration with DMSO was added to agar wells. The efficacy of extracts against bacteria was compared with antibiotics (i.e. amoxicillin, ampicillin, ofloxacin) and ayurvedic medicines (i.e., Karan Bindu, Ear-touch, Bilwa Tel). The petriplates were kept for incubation at $37^{\circ} \mathrm{C}$ for 24 $\mathrm{h}$ in BOD incubator. After incubation, the diameter of the zone of inhibition developed was measured (in millimeters). Each sample was performed in triplicates and the mean values were calculated.

Antifungal Testing: The assessment of antifungal activity of different extracts was carried out by poisoned food technique (Grover and Moore 1962; Nene and Thapilyal 2000). $250 \mu \mathrm{g} / \mathrm{ml}$ concentrations of different leaf extracts was prepared by using DMSO and then extracts were aseptically poured into sterile Petri plates followed by addition of melted sabouraud dextrose agar medium and swirled gently to achieve throughout mixing of the contents. $6 \mathrm{~mm}$ mycelial discs from the margins of 5 day old culture of test fungus was punched aseptically with a sterile cork borer and then put in the center of agar plates. Agar plates only with medium served as control. The efficiency of extracts was compared with antifungal drugs (i.e., ketoconazole, fluconazole, clotrimazole) and ayurvedic medicines (i.e., Karan Bindu, Ear-touch, Bilwa Tel). The plates were incubated at $25^{\circ} \mathrm{C}$ for 5-7 days in BOD incubator. Each sample was 
performed in triplicates, and the mean values were observed. Percentage inhibition of mycelial growth was calculated by using the following formula.

$$
I=\frac{(C-T)}{C} \times 100
$$

Where, $\mathrm{I}$ is the percentage inhibition, $\mathrm{C}$ the mean growth rate of control, and $\mathrm{T}$ treatment.

Determination of Minimum inhibitory concentrations: For determination of Minimum Inhibitory Concentration (MIC), two-fold serial dilution method (Aboaba, et al., 2006) was employed. Methanol extract was diluted double fold $(2: 2)$ with nutrient broth in a series of six test tubes. Concentrations of 50, 25, 12.5, 6.25, 3.12 and $1.56 \mathrm{mg} / \mathrm{ml}$ of crude $\mathrm{MeOH}$ extract were prepared separately and dissolved in $1 \mathrm{ml}$ of DMSO. Bacterial suspensions were prepared in test tubes with normal saline and incubated at $37^{\circ} \mathrm{C}$ for $6 \mathrm{~h}$ for making a turbid suspension. The bacterial suspension was adjusted to achieve a turbidity equivalent to McFarland turbidity standard 0.5 . An aliquot of $1 \mathrm{ml}$ of bacterial suspension $\left(1.5 \times 10^{6}\right)$ was inoculated into each tube. For control, test tube was inoculated with same quantity of sterile distilled water. All tubes were incubated at $37^{\circ} \mathrm{C}$ for $24 \mathrm{~h}$. The MIC was the lowest concentration of extract that did not permit any visible growth or no turbidity when compared with control was considered as the minimum inhibitory concentration.

Determination of Minimum inhibitory concentration (MIC) for fungi: The minimum inhibitory concentration (MIC) was evaluated as the minimum concentration of the plant extract inhibiting the absolute visible growth of test organisms on the agar plate following the method of Thompson, (1989). Experiment was performed to evaluate the toxicity nature of the extract at its minimum inhibitory concentration (MIC) by the poisoned food technique assay. The plates were incubated at $25^{\circ} \mathrm{C}$ for 5-7 days in BOD incubator. The observation of inhibition of mycelial growth was calculated.

Antioxidant activity: The radical scavenging activity of crude extracts of E. indica was easured by using DPPH assay (2, 2-diphenyl-1picrylhydrazyl) (Proestos, et al., 2013). The antioxidant assay was measured by decrease in the absorption of the DPPH radical solution after addition of crude extracts of $E$. indica in different concentrations from $50-250 \mu \mathrm{g} / \mathrm{ml}$ at $517 \mathrm{~nm}$. Different concentrations of $E$. indica leaf extract were added with $0.1 \mathrm{mM}$ of DPPH radical solution prepared in methanol. Then, $1 \mathrm{ml}$ of DPPH radical solution was added to sample solution $(3 \mathrm{ml})$ with various concentrations; the absorbance was determined by using a spectrophotometer at $517 \mathrm{~nm}$ against a blank. Ascorbic acid was used as reference. The percent inhibition of free radical using DPPH was calculated as:

$\%$ Inhibition $=\frac{\left(\text { Absorbance }_{\text {Control }}-\text { Absorbance }_{\text {Test }}\right)}{\text { Absorbance }_{\text {Control }}} \times 100$

Phytochemical screening: Preliminary qualitative phytochemical investigation was performed to find out the presence of phytoconstituents in the crude extracts of $E$. indica leaves as per standard qualitative methods (Evans, 2009; Scalbert, 1991). Phytoconstituents evaluated were phenols, glycosides, alkaloids, steroids, flavonoids, terpenoids, saponins and tannins.

\section{Results and Discussion}

Traditionally important medicinal plants have been used all over the world since ancient times. While, there has been great interest for the search of natural products as a new source of antibacterial and antifungal drugs (Somchit, et al., 2003; Bonjar, 2004). In the present investigation, antimicrobial efficacy of crude extract of $E$. indica leaves, ayurvedic, antibiotics and antifungal drugs against some selected pathogens causing ear infection are summarized in Table 1 and Table 2. The E. indica leaves extracts exhibited moderate antimicrobial activity. The $\mathrm{MeOH}$ extract showed maximum antimicrobial activity against $S$. epidermidis $(14.6 \pm 0.33 \mathrm{~mm})$ and moderately active against $H$. influenzae $(11.3 \pm 0.67 \mathrm{~mm})$ and $S$. pneumoniae $(10.0 \pm 0.58 \mathrm{~mm})$. Whereas acetone extract was found most effective against $A$. niger $(22.2 \pm 0.88$ $\mathrm{mm})$, A. flavus $(25.3 \pm 0.60 \mathrm{~mm})$ and A. fumigatus $(45.0 \pm 0.29 \mathrm{~mm})$ followed by methanol, petroleum ether and water extract. Amongst all the plant extracts in different solvents, $\mathrm{MeOH}$ extracts were found most effective. The $\mathrm{MeOH}$ extracts were compared with Ayurvedic, antibiotics and antifungal drugs (Table $1 \& 2$ ). So, for a comparative study, antibiotics and antifungal drugs 
Kaushal et al.

Table 1: Antimicrobial values of Erythrina indica leaves extracts against ear pathogens

\begin{tabular}{|l|l|l|l|}
\hline \multirow{2}{*}{$\begin{array}{l}\text { Solvent extracts } \\
(\mathbf{m g} / \mathbf{m l})\end{array}$} & *Diameters of the inhibition zone $\mathbf{( m m})$ & S. epidermidis \\
\cline { 2 - 4 } & H. influenzae & S. pneumoniae & $11.7 \pm 0.88$ \\
\hline Petroleum ether & $11.3 \pm 0.33$ & $12.0 \pm 0.82$ & $12.7 \pm 0.33$ \\
\hline Acetone & $10.7 \pm 0.67$ & $8.7 \pm 0.88$ & $14.6 \pm 0.33$ \\
\hline Methanol & $11.3 \pm 0.67$ & $10.0 \pm 0.58$ & $9.0 \pm 0.58$ \\
\hline Aqueous & $8.7 \pm 0.67$ & $10.3 \pm 0.88$ & $11 \pm 0.58$ \\
\hline Bilwa tel & $14.3 \pm 0.88$ & $12 \pm 0.33$ & $7.3 \pm 0.33$ \\
\hline Karan bindu & $10.3 \pm 0.88$ & $9 \pm 0.58$ & $7.7 \pm 0.33$ \\
\hline Ear touch & $17 \pm 0.58$ & $21.3 \pm 0.88$ & $18.6 \pm 0.33$ \\
\hline Erythromycin & $29.6 \pm 0.33$ & $24.6 \pm 0.88$ & $22 \pm 0.58$ \\
\hline Amoxicillin & $23.7 \pm 0.88$ & $34.7 \pm 0.33$ & $25 \pm 0.58$ \\
\hline Ampicilin & $23 \pm 0.58$ & $33.3 \pm 0.88$ & $32.3 \pm 0.33$ \\
\hline Ofloxacin & $28.3 \pm 0.67$ & $42 \pm 0.58$ & \\
\hline
\end{tabular}

*Zone of inhibition in millimetre $(\mathrm{mm})$ in triplicate expressed as means and standard error of means $($ mean $\pm \mathrm{SE}, n=3)$.

Table 2. Antifungal activity of Erythrina indica against ear pathogens by poisoned food technique

\begin{tabular}{|c|c|c|c|c|c|c|}
\hline \multirow{2}{*}{$\begin{array}{l}\text { Solvent } \\
\text { Extracts } \\
\text { (mg/ml) }\end{array}$} & \multicolumn{2}{|c|}{ Aspergillus niger } & \multicolumn{2}{|c|}{ Aspergillus flavus } & \multicolumn{2}{|c|}{ Aspergillus fumigatus } \\
\hline & $\begin{array}{l}\text { Mycelial } \\
\text { growth } \\
(\mathrm{mm})\end{array}$ & \% inhibition & $\begin{array}{l}\text { Mycelial } \\
\text { growth } \\
(\mathrm{mm})\end{array}$ & $\%$ inhibition & $\begin{array}{l}\text { Mycelial } \\
\text { growth } \\
(\mathrm{mm})\end{array}$ & $\begin{array}{l}\% \\
\text { inhibition }\end{array}$ \\
\hline $\begin{array}{l}\text { Petroleum } \\
\text { ether }\end{array}$ & $50.7 \pm 0.73$ & 20.45 & $36.3 \pm 0.44$ & 24.38 & $51.0 \pm 0.60$ & 32.69 \\
\hline Acetone & $22.2 \pm 0.88$ & 63.63 & $25.3 \pm 0.60$ & 47.29 & $38.3 \pm 0.73$ & 41.03 \\
\hline Methanol & $40.5 \pm 0.76$ & 39.39 & $31.3 \pm 0.73$ & 34.79 & $42.3 \pm 0.44$ & 50.90 \\
\hline Aqueous & $54.5 \pm 0.87$ & 17.42 & $38.7 \pm 0.88$ & 19.38 & $48.7 \pm 0.73$ & 37.82 \\
\hline Bilwa tel & $47.3 \pm 0.6$ & 28.79 & $34 \pm 0.58$ & 29.17 & $90.2 \pm 0.73$ & -17.31 \\
\hline Karan bindu & $59.2 \pm 0.44$ & 10.61 & $40.2 \pm 0.73$ & 16.25 & $81 \pm 0.58$ & -03.84 \\
\hline Ear touch & $32.8 \pm 0.44$ & 50 & $11.5 \pm 0.29$ & 76.04 & $51.5 \pm 0.6$ & 34.62 \\
\hline Clotrimazole & $6.7 \pm 0.17$ & 89.47 & $6.3 \pm 0.17$ & 86.88 & $6.5 \pm 0.29$ & 91.67 \\
\hline Ketoconazole & $6.2 \pm 0.17$ & 89.47 & $6.3 \pm 0.17$ & 86.88 & $6.8 \pm 0.17$ & 91.67 \\
\hline Fluconazole & $6.3 \pm 0.17$ & 89.47 & $6.2 \pm 0.17$ & 87.08 & $6.5 \pm 0.29$ & 91.67 \\
\hline
\end{tabular}

*Mycelial growth inhibition in millimetre $(\mathrm{mm})$ in triplicate expressed as means and standard error of means (mean $\pm \mathrm{SE}, n=3$ ).

Table 3. Phytochemical analysis of $E$. indica extracts

\begin{tabular}{|c|c|c|c|c|c|c|c|c|}
\hline \multirow{2}{*}{$\begin{array}{l}\text { S. } \\
\text { No. }\end{array}$} & \multicolumn{8}{|c|}{ Phytoconstituents } \\
\hline & Alkaloids & Flavonoids & Glycosides & Steroids & Terpenoid & Saponins & Phenol & Tannins \\
\hline 1. & PET & + & - & + & + & + & - & - \\
\hline 2. & $\mathrm{ACE}$ & + & + & + & + & - & + & + \\
\hline 3. & $\mathrm{MeOH}$ & + & + & + & - & + & + & + \\
\hline 4. & $\mathrm{H}_{2} \mathrm{O}$ & - & - & + & - & + & + & - \\
\hline
\end{tabular}




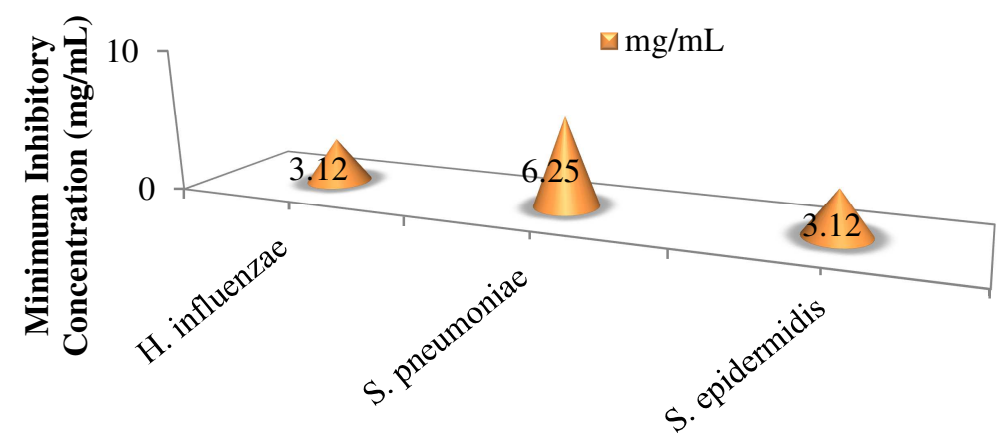

Fig. 1. Minimum inhibitory concentration of methanol extract of $E$. indica.

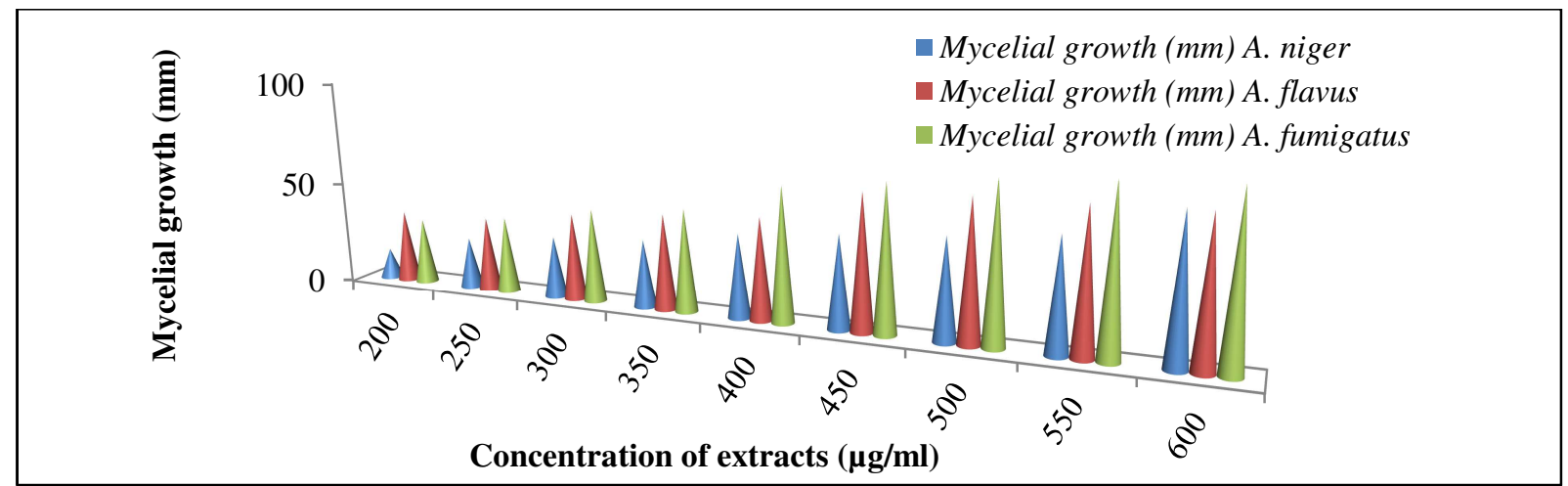

Fig. 2. Minimum inhibitory concentration of methanol extract of $E$. indica for fungi

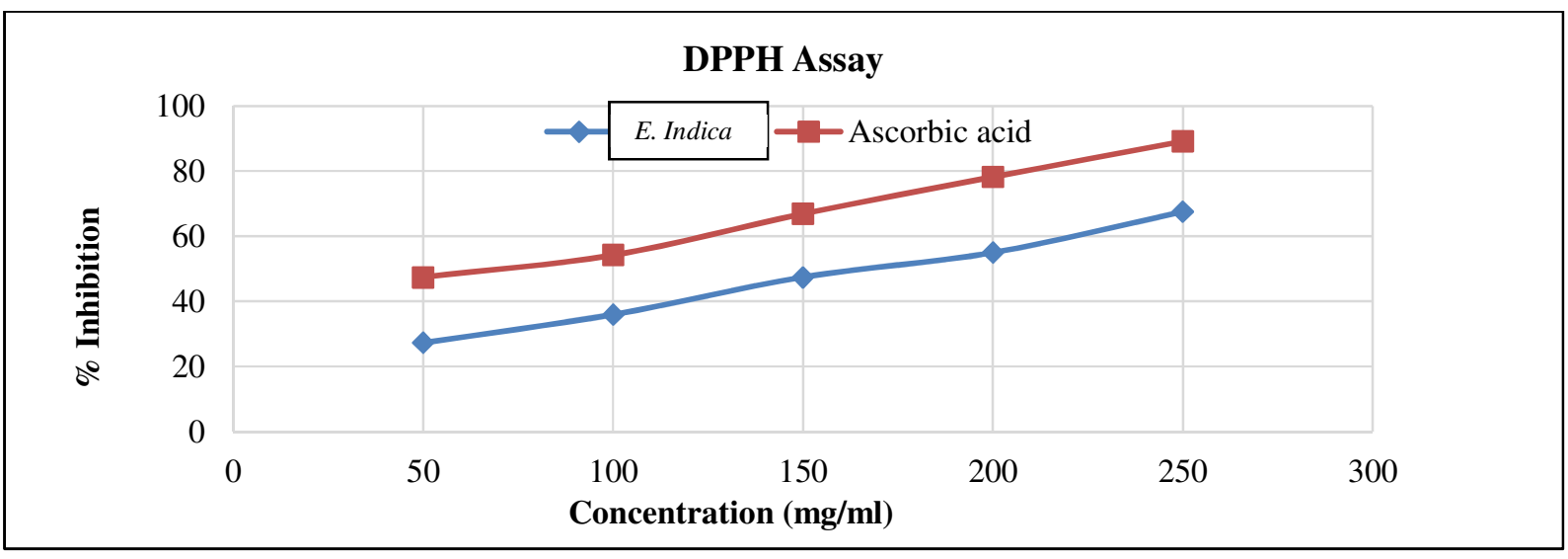

Fig. 3. DPPH free radical scavenging activity of methanol extracts of $E$. indica and Ascorbic acid

were found most effective in comparison to amoxicillin was also found effective against $S$. ayurvedic drugs and crude $\mathrm{MeOH}$ extracts. pneumoniae $(34.7 \pm 0.33 \mathrm{~mm})$ and S. epidermidis Ofloxacin was highly effective against $S . \quad(22 \pm 0.58 \mathrm{~mm})$ and $H$. influenzae $(23.7 \pm 0.88 \mathrm{~mm})$. pneumoniae $(42 \pm 0.58 \mathrm{~mm})$ and $S$. epidermidis All three fungal drugs, ketoconazole, fluconazole, $(32.3 \pm 0.33 \mathrm{~mm})$ and $H$. influenzae $(28.3 \pm 0.67 \mathrm{~mm})$, clotrimazole was found highly effective against 


\section{Kaushal et al.}

Aspergillus niger, Aspergillus flavus and i.e., $600 \mu \mathrm{g} / \mathrm{ml}$ only restricted the mycelial growth Aspergillus fumigatus. Whereas Ear touch was of tested fungi i.e., A. niger (68.93\%), A. flavus found active against $S$. pneumoniae $(21.3 \pm 0.88$ $\mathrm{mm})$ then $H$. influenzae $(17 \pm 0.58 \mathrm{~mm})$ and least active against $S$. epidermidis $(7.7 \pm 0.33 \mathrm{~mm})$, bilwa tel and karan bindu found least effective in comparison to antibiotics and antifungal drugs. While in other study, flavonoid extracts of $E$. indica for antimicrobial activity against $P$. aeruginosa, $B$. subtilis, S. aureus, S. pneumoniae, A. niger, $T$. reesie, $F$. moniliforme and P.funiculosum was screened. A. niger was observed resistant as none of the tested extract showed activity against this fungi (Agarwal and Sarin, 2014). While, ethanolic leaf extract of Erythrina variegate showed moderate activity against $P$. aeruginosa, $K$. pneumoniae, $E$. coli and B. cereus, $S$. aureus, $A$. niger and $A$. fumigatus (Muthukrishnan, et al., 2014). However, it was reported that ethanolic polyherbal extract in which Erythrina indica is one of plant was tested against five bacterial strains: $E$. coli, $P$. mirabilis, $G$. vaginalis, $P$. aeruginosa, $C$. albicans and $A$. niger by using disc diffusion method was found to possess significant antimicrobial properties (Deattu, et al., 2012). As, herbal medicine is a selective mixture of herbal constituent those are traditionally used in Ayurvedic, Homeopathic, and Native Indian medicine. The minimum inhibitory concentration of methanolic extract of $E$. indica leaves were shown varied effectiveness for all tested organisms i.e., S. pneumoniae, S. epidermidis and $H$. influenzae, A. niger, A. fumigatus, A. flavus indicated in Fig. 1 and 2. S. epidermidis and $H$. influenzae was found sensitive for methanol leaves extract than $S$. pneumoniae. It was found that the range of MICs for different bacteria ranged from $3.12-6.25 \mathrm{mg} / \mathrm{ml}$ (Fig. 1). The lowest MIC noted at $(3.12 \mathrm{mg} / \mathrm{ml})$ for $S$. epidermidis and $H$. influenzae whereas highest MIC recorded against $S$. pneumoniae $(6.25 \mathrm{mg} / \mathrm{ml})$. The minimum inhibitory concentration of most effective $\mathrm{MeOH}$ extract for fungal strains was also evaluated. The inhibition of mycelial growth at different concentrations of most effective $\mathrm{MeOH}$ extract on the inhibition percentage of $A$. niger, A. fumigatus, A. flavus are shown in Figure 2. The highest inhibition percentage $(80.13 \%)$ against $A$. fumigatus was observed at $600 \mu \mathrm{g} / \mathrm{ml}$ while the lowest inhibition (14.4\%) against $A$. niger was obtained with 200 $\mu \mathrm{g} / \mathrm{ml} \mathrm{MeOH}$ extract. The highest concentration

(68.75\%) and A. fumigatus (80.13\%). The nature of fungitoxicity of $\mathrm{MeOH}$ extract manifested a better MIC against tested organisms. The susceptibility of all tested microbes against methanolic extract of $E$. indica leaves might be due to the presence of bioactive phytoconstituents in the crude extracts. While in other study, the value of MIC at different concentration for extracts of $E$. indica was recorded i.e., $0.019 \mathrm{mg} / \mathrm{ml}$ noted for root and leaf extract against $B$. subtilis, where $0.625 \mathrm{mg} / \mathrm{ml}$ for leaf extract against $S$. aureus, and $P$. aeruginosa and also for stem extract against $P$. funiculosum (Agarwal and Sarin, 2014).

The Erythrina indica leaves extracts were studied for the antioxidant activity was evaluated by DPPH free radical scavenging activity. The DPPH radical inhibition percentage of $E$. indica leaves at different concentrations is shown in Figure 3 and is compared to the standard compound ascorbic acid. The $\mathrm{IC}_{50}$ value of methanol extract was 166.9 $\mu \mathrm{g} / \mathrm{ml}$, which was found higher than that of standard ascorbic acid, $70.06 \mu \mathrm{g} / \mathrm{ml}$. A lower value of $\mathrm{IC}_{50}$ represents high antioxidant activity. Therefore, the IC50 value of methanol extract was found lower when compared to standard ascorbic acid. Hence, it can be stated that methanol extract does possesses good free radical inhibiting efficiency, but not better than that of standard ascorbic acid. Whereas other reports also support that methanol extract of E. indica stem bark possess antioxidant properties. DPPH which is a stable free radical used to measure radical scavenging potential of extracts. The $\mathrm{MeOH}$ extract had considerable effect due to its scavenging potential in terms of hydrogen donating ability. The decrease in absorbance was observed with the addition of different concentration of extract (50$250 \mu \mathrm{l} / \mathrm{ml}$ ), is taken as a measure of the extent of radical scavenging. While ascorbic acid showed highly significant scavenging effect. In earlier study, it was reported that with increase in concentration of $E$. indica methanolic bark extract from $50-250 \mu \mathrm{g} / \mathrm{ml}$, the efficient scavenging effects occurred on the DPPH radical (Moon, et. al., 2010). The crude methanolic extract of $E$. indica leaves posses free radical scavenging and antioxidant capacity (Mujahid, et al., 2014). The preliminary phytochemical analysis for extracts of $E$. indica 
leaves are shown in Table 3. E. indica leaves extract shows the presence of glycosides, flavonoids, saponins, tannins, alkaloids, steroids and phenol. In earlier studies, the presence of alkaloids, flavonoids, sterols, triterpenoids and carbohydrates were also reported by phytochemical analysis (Pandaya, et al., 2012; Amir et al., 2011). Traditionally the plant has been used in nervine sedation, opthalmia, asthma, epilepsy, antiseptic, etc (Khare, 2007). Pharmacologically important characteristics which have been in practice traditionally i.e., neuromuscular blocking, smooth muscle relaxant, CNS depressant, analgesic and hydrocholerectic action and also used in fever, inflammation, bacterial infection, insomnia, helminthiasis, cough, cuts and wounds (Ghosal et al., 1972; Haque et al., 2006). Flavonoids and Saponins have been studied which possess a wide range of biological activities. As this is well known phenomenon that plant synthesized them mainly due to microbial infection, hence they possess antimicrobial property (Deattu et al., 2012). However, Traditional practitioner mostly use water as solvent whereas in the present study, methanol extract exhibited best antimicrobial activity in comparative to aqueous extract which did not found much effective against bacteria as well as fungi. Hence, it is concluded that organic compounds are good solvents as compared to aqueous and petroleum ether (Ahmed et al., 1998). Leaf extract of E. indica in organic solvent showed much efficacy than aqueous solvent. Thus, it is having a great potential to be used for therapeutic purpose to control ear infection.

\section{Conclusion}

E. indica is an essential medicinal plant used traditionally for therapeutic purpose from ancient times. The present work deals with antimicrobial activity against bacterial strains (S. pneumoniae, $S$. epidermidis, $H$. influenzae) and fungal strains (A. niger, A. fumigatus, and A. flavus), antioxidant activity as well as phytochemical analysis of leaves of $E$. indica for ear infection were investigated. Findings from this study indicated the presence of bioactive compounds that restricted the growth of bacteria as well as fungi but they showed varied effectiveness. The leaves of $E$. indica possess potent antimicrobial and antioxidant activity than the known herbal drugs used for comparative study. However, it is suggested that further detailed studies should be carried out for bioactive components and therapeutic properties of $E$. indica in curing ear diseases. Thus, $E$. indica can provide a natural cure against microbial infections in ear as well as a way for the preparation of novel drugs.

\section{Acknowledgement}

The authors are grateful to the Head, Department of Botany and Microbiology, Gurukul Kangri University, Haridwar for providing the laboratory facilities to enable this research to be carried out.

\section{References}

Aboaba, O.O., Smith, S.I., Olude, F.O. 2006. Antibacterial effect of edible plant extract on Escherichia coli 0157: H7. Pakistan Journal of Nutrition. 5: 325-327.

Agarwal, M. and Sarin, R. 2014. Screening of antimicrobial potential of flavonoids extracted from Erythrina indica. International Journal of Pharma Research \& Review. 3: 21-27.

Ahmed, I., Mehmood, Z., Mohammad, F. 1998. Screening of some Indian medicinal plants for their antimicrobial properties. Journal Ethnopharmacology 62: 183-193.

Amir, F., Yam, W.S., Koay, Y.C. 2011. Phytochemical constituents and biological activities of Erythrina indica. European Journal of Chemistry. 2: 561-565.

Aneja, K.R., Sharma, C., Joshi, R. 2012. Antimicrobial activity of Terminalia arjuna Wight \& Arn.: an ethnomedicinal plant against pathogens causing ear infection. Brazilian Journal Otorhinolaryngology. 78: 68-74.

Barber, D.A. and Harris, S.R. 1994. Oxygen Free Radicals and Antioxidants: A Review: The use of antioxidant vitamin supplements to scavenge free radicals could decrease the risk of disease. American pharmacy. 34: 26-35.

Bonjar, S. 2004. Evaluation of antibacterial properties of some medicinal plants used in Iran. Journal Ethnopharmacology. 94:301-305.

Cao, G., Sofic, E., Prior, R.L. 1996. Antioxidant capacity of tea and common vegetables. Journal Agricultural Food Chemistry 44: 3426-3431.

Deattu, N., Suseela, L., Narayanan, N. 2012. Evaluation of antibacterial and antifungal activates of ethanolic polyherbal extract. Journal of Drug Delivery \& Therapeutics 2: 53-55. 


\section{Kaushal et al.}

Dhingra, P.L. and Dhingra, S. 2014. Diseases of ear, nose and throat \& head and neck surgery. 6th ed. Reed Elsevier India Pvt Ltd, New Delhi.

Evans, W.C. 2009. Trease and Evans pharmacognosy, 16th edn. Elsevier Health Sciences.

Ghosal, S., Dutta, S.K., Bhathacharya, S.K. 1972. Erythrinachemical and pharmacological evaluation II: Alkaloids of Erythrina variegata L. Journal of Pharmaceutical Sciences. 61: 1274-1277.

Grover, R.K. and Moore, J.D. 1962. Toxicometric studies of fungicides against brown rot organisms, Sclerotonia fructicola and S. laxa. Phytopathology 52: 876-880.

Haque, R., Ali, M.S., Saha, A., Allimuzzaman, M. 2006. Analgesic activity of methanolic extract of the leaf of Erythrina variegata.Journal of Pharmaceutical Sciences. 5: 77-79.

Jagessar, R.C., Mohamed, A., Gomes, G. 2008. An evaluation of the antibacterial and antifungal activity of leaf extracts of Momordica charantia against Candida albicans, Staphylococcus aureus and Escherichia coli. Nature and Science. 6: 1-14.

Jesupillai, M., Jasemine, S., Palanivelu, M. 2008. Diuretic activity of leaves of Erythrina indica Lam. International Journal of Green Pharmacy. Oct-Dec: 218-219.

Khare, C.P. 2007. Indian Medicinal Plants: An Illustrated Dictionary. Springer, New York pp 246-247.

Kumar, S., Navneet, Tiwari, M.M., Gautam, S.S. 2014. Antimicrobial and phytochemical screening of Olea europaea Linn. extracts against dental pathogens. African Journal of Microbiology Research. 8: 3373-3377.

Maobe, M.A.G., Gitu,, L., Gatebe, E., Rotich, H., Karanja, P.N., Votha, D.M., Wambugu, J., Muingai, C. 2013. Antimicrobial activities of eight selected medicinal herbs used for the treatment of diabetes, malaria and pneumonia in Kisii region, Southwest Kenya. Global Journal of Pharmacology. 7: 25-33.

Moon, K., Katolkar, P., Khadabadi, S.S. 2010. In vitro antioxidant activity of methanolic extract of Erythrina indica. Der Pharmacia Lettre. 2: 16-21.
Muthukrishnan, S., Palanisamy, S., Santhanam, I., Muthukrishnan, G.K. 2014. Phytochemical screening and antimicrobial activity of Erythrina variegata. World Journal of Pharmacy and Pharmaceuutical Sciences. 3: 680-690.

Nene,Y. and Thapilyal L. 2000. Poisoned food technique. Fungicides in plant disease control. 3rd Edn. Oxford and IBH Publishing Company, New Delhi.

Pandya, D.J., Yadav, E.N., Kardani, B.R., Joshi, K.K., Desai, T.R., Patel, V.L. 2012. Phytopharmacognostic study of leaves of Erythrina indica. Research Journal of Pharmaceutical Biology and Chemistry Science. 3: 127.

Proestos, C., Zoumpoulakis, P., Sinanoglou, V.J. 2013 Determination of plant bioactive compounds, antioxidant capacity and antimicrobial screening. Focusing on modern food industry. 2: 26-35.

Roland, P.S. and Stroman, D.W. 2002. Microbiology of acute otitis externa. Larygoscope 112: 166-177.

Rosenfeld, R.M., Brown, L., Cannon, C.R., Dolor, R.J., Ganiats, T.G., Hannley, M., Kokemueller, P., Marcy, S.M., Roland, P.S., Shiffman, R.N., Stinnett, S.S., Witsell, D.L. 2006. Clinical practice guideline: acute otitis externa Otolaryngology Head Neck Surgury. 134: 4-23.

Sakat, S.S. and Juvekar, A.R. 2010. Comparative Study of Erythrina indica Lam. (Febaceae) Leaves Extracts for Antioxidant Activity. Journal Young Pharmacology. 2: 63-67.

Scalbert, A. 1991. Antimicrobial properties of tannins. Phytochemistry. 30: 3875-3883.

Shariff, N., Sudarshana, M.S., Umesha ,S., Hariprasad, P. 2006. Antimicrobial activity of Rauvolfia tetraphylla and Physalis minima leaf and callus extracts. African Journal Biotechnology. 5: 946-950.

Somchit, M.N., Reezal, I., Nur, I.E., Mutalib, A.R. 2003. In vitro antimicrobial activity of ethanol and water extracts of Cassia alata. Journal Ethnopharmacology. 84:1-4.

Thompson, D.P. 1989. Fungitoxic activity of essential oil components on food storage fungi. Mycologia. 81(1):151153

Mujahid, Md., Siddiqui, H.H., Hussain, A., Hussain, Md. S 2014. In- vitro evaluation of free radical scavenging activity of Erythrina indica leaves. Journal of Drug Delivery \& Therapeutics 4: 49-54
Young, I.S. and Woodside, J.V. 2001. Antioxidants in health and disease. Journal Clinical Pathology. 54: 176-186. 